\title{
Ankara'da Intihar Girişimleri Üzerine Bir Çalışma
}

\author{
I. Sayll*, A. Oral*, S. Güney*, N. Ayhan** \\ Ö. Ayhan***, H. Devrimcik****
}

Özet : Turkiye'de intihartar (1989'da 2.5/100.000) şimdilik bir sorun gibi gözökmese de intihar girişimlerine ilişkin güvenilir sayısal veriler mevcut değjldir. Bu soruna en azından bir büyük kentte açıkık kazandirmak amacıyla bu araştırma planlanmıştır.

Araştırmamizda Ankara'daki tüm acil servislere 1990 ydi içinde intihar girişimi ile yapilan başvurular retrospektif olarak kaystlardan taranarak belirlenmiştir. Sonuçiar olgulara ait demoğrafik özellikler, büyük kent yaşamı dikkate alınarak ve literatür bulguları doğrultusunda tartı̧̧ımışıtır.

Summary: The suicide rate in Turkey has not always been high. It was found to be 2.5 per 100.000 in 1989. In spite of this rate, specialists in the field know that the parasuicide rate is much higher than the suicide rate. Since reliable statistical data on the subject of parasuicide is not available we have planned to study this subject in Ankara.

In this study the records of all emergency services have been reviewed and the data has been collected on suicide attempts in Ankara in 1990.

The results have been discussed and compared focusing on the social changes and sociocultural features and related research findings.

Intihar olgusu uzun süreden beri toplum sağlığı alanında çalışan araștırmacı ve klinisyenlerin ilgi alanı haline gelmiştir. Intihar olgusu beraberinde iki önemli kavramı gündeme getirmektedir; tamamlanmış intiharlar (ki burada sonuç olümdür) ve intihar girişimleri. İntihar literatüründe tamamlanmış intiharlara ilişkin bilgiler daha sistematik ve dolayısıyla güvenilir olarak karşımıza çıkmaktadır (Taneli, 1981). Ancak intihar girişimlerine ilişkin bilgiler için aynı şey her zaman söz konusu değildir.

Ülkemizde intihar konulu araştırmalara bakıldığında çoğunun bazı illeri (Kucur ve Aktan, 1987; Gürgen 1989), ergenler, cocuklar ya da psikiyatrik hastalar gibi küçük grupları (Lester,

\footnotetext{
A.U. Psikiyatrik Kriz Uygulama ve Araştıłma Merkezi

${ }^{\star \star}$ S.S.K. Ank. Hst. , ${ }^{* \star *}$ O.D.T.Ũ , ${ }^{\star \star \star \star}$ A.Ü. T.F Psikiyatri A.B.D.
}

içi, 1990; Palabıyıkoğlu, 1990; Sonuvar, OKktem, 1986;Aydın ve ark., 1988; Sayıl ve ark., 1988) hedefleyen çalışmalar olduğu gözlenmektedir. Bir grup araştırma da çeşitli hastanelerin acil servislerinde dar zaman aralıkiarı seçilerek düzenlenmiştir (Kucur ve Aktan, 1987; Çakmak ve ark., 1988; Özşahin ve ark., 1988).

1986 yilı için GATA acil senvisine başvuran intihar girişimli hastalar ele alındığında (Ózşahin ve ark. 1988) 20-30 yaş grubu intihar girişimi açısından risk grubu olarak değerlendirilmiştir. Çakmak ve arkadaşları (1988) ile Kucur ve Aktan (1987) tarafından yapılan çalışmalarda is $\theta$, tisk altındaki yaş grubu 15-24 olarak bulunmuştur. Çalışmalarda, en sık kullanılan intihar girişimi yönteminin kendini zehirleme olduğu ve bunun literatürle uygunluk gösterdiği belirtilmiştir (Blumenthal, 1988). Ayrıca intihar girişiminde bulunanların daha çok kadınlar olduğu ve erkeklerden iki kat fazla girişimde bulundukları bildirilmektedir. 
Kucur (1988) tarafindan yapilan çalımada ise intihar davranışı için ilkbahar ve yaz aylarının risk dönemierini oluş̧urduğu bulunmuş̧ur.

Ozşahin ve arkadaşarınca yapłlan çalışmada (1988) hastaların ancak \% 43.4'ünün psikiyatri kliniğine ulaşabildiŏi saptanmıł̆ır.

Eizersdorfer ve arkadaglarinca (1991) Vyana'da Intihar girisim insidansinı belirlemek amacıyla yapılan çalısmada 5 farklı kaynaktan elde edilen bilgiler kanșilaştıılmıs ve tamamlanınış intiharlarda kadın-erkek oranının eşittenmeye başladiğı, ayruca son 5 ylldaki intihar girişimlerinde ônemli düşmeler olduğu bulunmuştur. Ancak intihar girişimleri hakkında sağlıki ve güvenilir bilgiler olde oditemedigi, mevcut sagilk sisteminde bu hastalarin ayaktan ya da yatarak değerlendirilip, tedavi edilmesinde aksaldıklar olduğu belirtilmiştir.

Ülkemizde tamamlanm!ş Intiharlar için DiE tarafindan sistematik olarak bilgi elde otmemize rağmen, intihar girişimłerine ait bigilerimiz sadece az sayıda araştırmalardan ve hastane kayıtkarindan golmoktedir (Taneli, 1981). Konuya koruyucu halk sağlığı açısından bakıldığında özellikle intihar girisimierine iliskin sistematik bilgilere intiyac vardir. MOdahale ve önleme açısından risk gruplarmın değerfendirilmesi ve ozelliklerinin belirlenmesi konunun temelini oluşturmaktadır.

Bu cerçevede bu arastuma, Ofkemizde koruyucu halk sağlığı alanında yenl kurulmuş bir merkez olan Krize Müdahale Merkezince hizmet verdiği Ankara sehri içinde gerçekteşitilimiştir.

Bu calışmanın amaci, Ankara Içindeki hastanelerin acll servislerine gelen intihar girişimi vak'alarının ozelliklerini sistematik olarak ortaya koyarak, Ankara için intihar girişim insidansinı ve bazı sosyodemoğrafik özelliklerle ilişkisini degerlendirmek ve Krize Madahale Merkezinin intihar ónleme acisindan vereceğl hizmetler için yol gösterici bilglier elde etmektir.

\section{YONTEM}

Çalışmanın amact doğruttussunda, Ankara için hasta potansiyelinin \% 95'ini taşıdığ saptanan 9 hastaneye ait 1 Ocak 1990-31 Aralik 1990 tarihleri arasındak acil servis kayıtları tararmiştır. Ayrica intihar girişimlerinin adfi vak'a nitelił̧i taşıması nedeniyle hastane polis kayitlarindan da yarartanilmıstur.

Taramada her intihar girişimll vak'a yaş, cinsiyet, medeni durum, eğttim, mesiek, yaşanilan semt, inthar yöntemi, hastanenin uyguladiğı terapötlik yakaşım vo intihar zamant (ay vo saai olarak) de jişkenleri açısından incelenmiştir. Ancak 1901 inthar girisiml vaka kaytlannm hiç birisinde eğtim değjşkenine ilişkin blt bilgi bulunamadığından, bu değtşken daha sonra araştırma dışı bırakılmak zorunda kalınmıştır. Istatistiksel analizlerde \% değerleri değ̈şikenlerin her biri için saptandığı denok sayıs üzerinde hesaplanmıştır.

\section{BULCULAR}

Tarama sonucu toplam 1901 Intihar girişm vak'ası saptanmuştr. Tarama yapulan hastane ve bu hastanelere başvuran intihar girişimli vakłalarn say ve yozdeleri Tablo I'de verilmiştir. Tablodan da anlaşlacağ gibi \% 28.8 de Numune Hastanesi başta gelmektedir.

Tablo I : Intihar Girigimi Vak'alarnm Hastanelene Côre Dayjulim

\begin{tabular}{|c|c|c|}
\hline HASTANELER (AClLS.) & SAYI & YÜZDE \\
\hline AÜTF Cebeci Hst. & 178 & 9.4 \\
\hline HATF Hst. & 141 & $7: 4$ \\
\hline $\begin{array}{l}\text { Numune Hst. } \\
\text { Ankara Hat. }\end{array}$ & 384 & $\begin{array}{l}28.8 \\
20.2\end{array}$ \\
\hline Acil Yrd. veTrm.ttst. & 20 & 1,1 \\
\hline GUTFF Hst. & 194 & 10.0 \\
\hline GATA Hst. & 183 & 9.6 \\
\hline SSK Ank.Hst & 190 & 10.0 \\
\hline Topan & 1900 & 1000 \\
\hline
\end{tabular}

Insidans: 1990 yil için 9 hastanenin acil servis kayitlarından 12-70 yaş arasında 1901 vak'a saptanmısțtır. Vak'aların 6451 erkek 12411 kadındir. 15 vak'anın cinsiyetine ilişkin bir kayıta rasttanmamiştır. Bu vak'a sayılarmdan yola çkarak elde edilen değer Ankara ili için intihar girişim oranı 100.000 'de 107 dir.

Intihar girişim vak'alarının sayısı, şehirdoki tamamlanmış intiharların " sayıst " ill's karşilaştırıldı̆̆ında (verilen yul için DiE verilerinden) sonucłar aynı yas grubu için 58 erkek ve 24 kaden olmak uzere toplam 82'dir. Diğer yandan Ankara ili için tamamlanmış intihar oranı 100.000 'de 4 olup, intihar girisimlerinin tamamlanmıs intiharlara oranı 26.7/1'dir (DiE, 1990; Sayll, 1987).Bu oran erkekler icin 67 Iken, kadinlar igin 139 dur.

Cinsiyet ve Yaş: Genel bulgular intihar girisimlerinin daha çok genç grupta ve erkeklere nazaran kadinlarda daha fazla olduğunu 
göstermiştir. Bu çerçevede bat/ ülkelerinde esittlenmeye başlayan erkek-kadın orani (Diekstra, 1981,1989 ) bu çalışmada 1/2 olarak bulunmuştur.

Tablo li: Intihar Girişimi Vak'alarının Cinsiyet ve Yaşa Göre Dağlum

\begin{tabular}{|l|c|c|}
\hline Cinsiyet & Sayı & $\%$ \\
\hline Kadın & 1241 & 65.33 \\
Erkgk & 645 & 33.88 \\
Bilinmeyen & 15 & 0.79 \\
Toplam & 1901 & 100.00 \\
\hline Yaş & Sayı & $\%$ \\
\hline $00-14$ & 66 & 3.5 \\
$15-24$ & 928 & 48.8 \\
$25-34$ & 407 & 21.5 \\
$35-44$ & 148 & 7.8 \\
$45-54$ & 35 & 1.8 \\
$55-64$ & 18 & 0.9 \\
65. & 4 & 02 \\
Bilinmeven & 295 & 15.5 \\
\hline Tax'm & 1901 & 100.0 \\
\hline
\end{tabular}

Yaş faktörüne bakıldığında, 15-24 (\% 57.5) ve 25-34 (\% 21.5) olmak üzere iki farkdı yaş grubunda yükselme görülmektedir. Batı Avrupa'da yapılan bazı çalışmalar Türkiye ile karşıllaştırıdığında yaş grupları açısından farklı bir dağılım görülmektedir. Yükselme saptanan yas grupları 25-34 iken (Diekstra, 1981, 1989; Bille-Brahe, 1990) bu çalışmada 15-24 ołarak bulunmuştur. Yaş ve cinsiyet dağılımı Tablo li'de verilmiş̧tir.

Intihar Yöntemi: Kadın ve erkek için ilaç alma veya kendini zehirleme yöntemi \% 88.21 ile ilk sırayı alırken ikinci sırayı kesi yöntemi oluşturmaktadır. Kadınlarla erkekler karşılaşıırıldığında, erkeklerin kadınłara oranla bir intihar girişim yöntemi olarak kesiyi tercih ettlkleri söylenebilir (kadın: \%2.67, erkek: \%19.90). Bu bulgular ilgili literatürde, intihar girişim yöntemi konusunda kadınların tercihinin kendini zehirleme olduğu, erkeklerin ise daha ciddi yöntemler seçtikleri sonucuyla uygunluk göstermektedir (Diekstra 1981, 1989; Bille-Brahe, 1990). Vak'aların yakıaşık \% 4'ünde çeşiti intihar girişim yönteminin yanısıra alkol alımı saptanmışır. Kuflanılan intihar girişim yöntemleri Tablo III'te ayrıntılı olarak verilmiş̧tir.
Tablo Ill: Intlhar Giriģimierinde Kullanilan Yōntemlerin Dağılımı

\begin{tabular}{|l|r|r|}
\hline Intihar Girisimi yöntemieri & San & \multicolumn{1}{c|}{$\%$} \\
\hline Ilaç ve toksik madde alım! & 1677 & 88.21 \\
Kesi & 158 & 8.32 \\
Ast & 7 & 0.36 \\
Attama & 9 & 0.48 \\
Ateşli silah & 1 & 0.05 \\
Yakma & 1 & 0.05 \\
Tüpgaz & 13 & 0.68 \\
llaç ve kesi & 8 & 0.43 \\
llaç ve silah & 1 & 0.05 \\
Diğgr & 26 & 1.37 \\
\hline Toplam & 1901 & 100.00 \\
\hline
\end{tabular}

Meslek (N:142): Bu 142 vak'anin \% 30'unun ŏğrenci, \% 24ünùn ev hanımı olduğu görülmektedir. Geri kalanlar ise, memur $(\% 17)$, iş̧̧i (\% 18), emekli $(\% 3)$, issiz $(\% 5)$ ve sertest mestek sahiplerinden (\% 3) oluşmaktadır.

Medeni Durum (N:154): Vak'aların \% 39.61' evli, \% 58.44'ü bekar ve \% $1.95^{\prime}$ ' dul olarak saptanmıştır.

Inthar Girişim Zaman (ay (N:1850) ve saat (N:829) olarak) : Haziran (\%10.60) ve Ağustos (\% 10.48) ayłarı intihar girişimlerinin en çok gözlendiği aylar ofmuştur. Intihar girişimi saatine bakııdığında $\% 20.39$ iie 18.30-21.30 saatleri arasinda intihar girişimlerinin yoğunlaştı̆̆ı bulunmuştur (bkz. Şekil 1 ve 2).

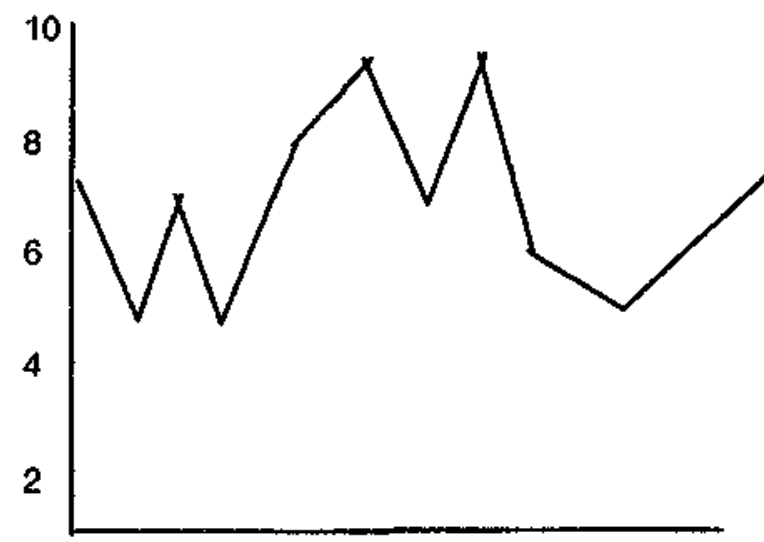

$\begin{array}{llllllllllll}1 & 2 & 3 & 4 & 5 & 6 & 7 & 8 & 9 & 10 & 11 & 12\end{array}$

Şekil 1 : Intthar Giriģimlerinin Aylara Göre Dağıımı 


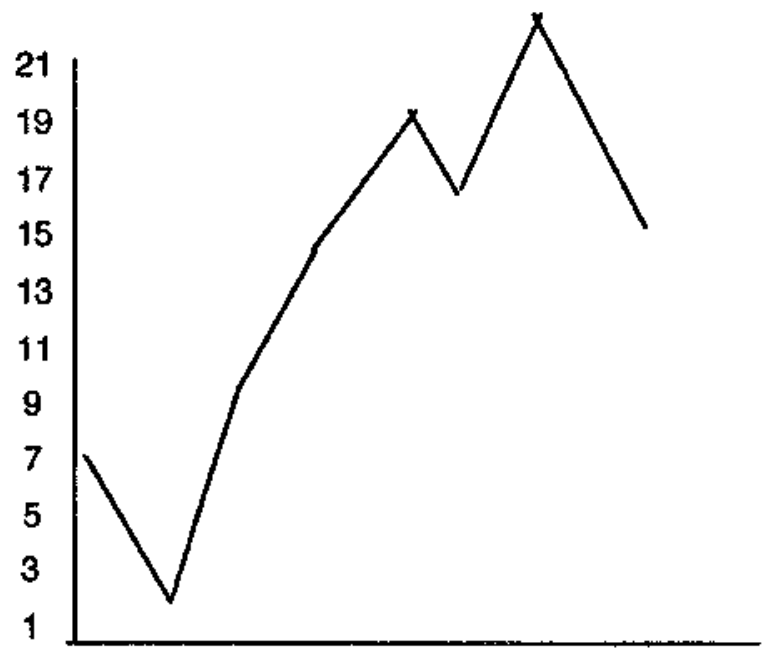

$\begin{array}{lllllllll}24-03 & 03-06 & 06-09 & 09-12 & 12-15 & 15-18 & 18-21 & 21.24\end{array}$

Şekil 2: Intihar Girişimlerinin Saatlere Göre
Dağılımı

Müdahale ve Öneri(N:1631): Vak'aların \% 50.65 'ine mayi takıldığı, lavaj ve kusturma uygulandığı saptanmıştır. Bu bulgu, intihar girişim yöntemlerinin daha çok kendini zehirleme olmasiyla parelellik göstermektedir. Gerekli tedavi yapıldıktan sonra vak'aların $\% 4.48$ 'ine yatış kararı verilmiştir. Deneklerin \% 2.51 'inin herhangi bir ileri tedaviyi reddettiği saptanmıştır. Yine müdahaleden sonraki süreç için vak'aların \% 59.3'b eve gönderilirken ancak \% $15^{\prime} i$ için psikiyatrik bağlantı kurulmaya çalışıdığı gözlenmiştir. Ancak bu sürecin tamamlanıp tamamlanmadığı acil servis kayıttarından belirtenememiştir.

Yaşanılan Bölge (N:559): \% 40 ile ilk bölge Mamak, \% 30 ile Çankaya ikinci bölge olarak belirlenmiştir. Altındağ ilçesinde \% 15, Keçiören ilçesinde ise \% 10 olarak dağıllım gözlenmiştir. Yaşadıkları semtin saptanabildiği vak'alar ancak belli iki hastanede yoğunlaştığı için genel değerlendirmede dikkatli olunması gerektiği düşünülmektedir.

Memleket (N:869): lik sırada Ankara (\% 35.90) geimiş, \% 6.2 ile Yozgat ikinci sırada yer almıştır. Üçüncü î Çorum $(\% 4.6)$ ve dördüncü it Sivas (\%4.5) olarak saptanmıştır. Illk sıraları leç Anadolu bölgesine ait illerin aldığı gözlenirken beşinci sırayı tstanbul'un aldığı görülmektedir (\% 3.01).

\section{TARTIŞMA}

Calışmadan elde edilen sonuçlar genel olarak değerlendirildił̧̧inde, intihar girişimlerinin kadın ve genç grupta yoğunlaşması, daha çok liaç ve toksik madde alımı yoluyla intihar girişiminde bulunulması ilgili literatürle uygunluk göstermektedir (Diekstra, 1981, 1989; Alderson, 1985; Bille-Brahe 1990; Cakmak ve ark., 1988; Aydin ve ark., 1988; Kucur 1988; Özşahin ve ark., 1988).

Intihar girişimlerinin daha çok haziran ve ağustos aylarında gözlenmesi Parker ve Walter'ın (1982) intiharla ilgili çalışmasıyla uygunluk gőstermektedir. Aynı sonuç Kucur (1988) tarafından da tekrarlanmıştır. Genel olarak bahar ve yaz ayları kritik dönemleri oluşturmaktadır. Bu sonuç değerlendirmeye tabi tutulduğunda eğitim ve tatil dönemleriyle bağlantı kurulabilir. Haziran ayı eğitim dönemine ait sonuçarı ı̈ örenildiği bir döneme denk gelirken, ağustos ayının da yine bütūnlème sınavlarının başladığı ve tatil ile tatil sonrası ilişkilerin yoğunlaştığı bir dönemi oluşturduğta söylenebilir. Böylelikle iletişim problemlerinin daha fazla su yüzüne çıkmıs olabileceği akla gelmektedir. intihar girişimli grubun daha çok gençlerden oluşması ve öğrencilerin çoğunlukta olması eğitim dönemiyle bağlantı kurulmasına destek verir gözükmektedir.

Intihar girişimlerinin daha çok akşam saatlerinde görülüyor olması yine, ev-aile içi iletişimin başladığı, tüm aile üyelerinin genel çalışma koşullarından dolayı evde oldukları saatleri oluşturmaktadır. Bu, iletişimin başlama döneminde girişimin 'ortaya çıkması, girişimin ölüm amacı taşımayarak yardım çağrısı çaresizlik olması şeklinde düşünülebilir. Ayrıca yatış kararının $\% 4.48$ olmasının da buna destek verdiği düşünülmektedir. Ancak intihar girişimlerinin temelde psikolojik yardım gereksinimi ele alındığında, \% 15 'lik psikiyatri bağlantısı gerekli psikolojik yardımın eksikjiginini göstermektedir (Ekşi, 1988).

Kucur ve Aktan'ın (1987) 1986 yili için Konya ilinde yaptıkları çalışmada intihar girişim insidansı, $100.000^{\prime} d e 17.61$ olarak bulunmuştur. $15-24$ yaş grubu ise bu çalışmada olduğu gibi en fazla risk altındaki grubu oluşturmaktadır (100.000/44.54). Çalışmamızda 100.000/107 olarak bulunan intihar girişimi insidansına göre daha yüksektir.

Konya ili için intihar girişimlerinde cinsiyet açısından yapılan karşılaştırmada kadınların erkeklerden iki kat fazla girişimde bulundukları saptanmış olup, bu sonuç bizim araş̧ırmamızda da 
tekrarlanmıştıt. Medeni durum açısından bakıldığında bekariarda intihar girişiminin daha fazla olduğu bulunmuştur. Ancak bu sonuç intihar girişimłerinin daha çok genç grupta ve öğrencilerde fazla oluşuyla açıklanabilir.

Konya jli için yapılan çalışmaya mevsimler açısından bakıldığında intihar için yaz ayları risk faktörünü oluştunurken, girişimler için ilkbahar ve yaz ayları ön plana çıkmaktadır. Bizim çalışmamızda ise girişim için saptanan aylar yaz mevsimine karşılık gelmektedir (Haziran, Ağustos).

Bu çalışma, sonuçları açısından, genel olarak değerlendirildiğinde genel literatür bulgularıyla uygunluk gösterdiği söylenebilir. Ancak yapılacak yorumlarda çalış̧mada gözlenen eksik yönlerin dikkate alınması gerektiği ve kesin yorumlar için daha sistematik ve güvenilir kayitlara gereksinim olduğu düşünülmektedir.

Etzersdorfer ve arkadaşlarınca (1991) 1989 yll için Viyana şehrinde yapılan çalışmada karşılaşılan güçlükler, tedavi ve önleme açısından intihar girişimleri hakkında sağlıklı bilgi edinememe sorunu vurgulanmıştır. Ayrıca mevcut sağlık kurum ve kurułuşłarının intihar girişimli hastaya müdahale edecek ortam, bilgi ve gereçleri sağlama, onları izleme konusunda yetersiz kaldığı belirtilmiştir. Bizim çalışmamızda da acil sağlık hizmetieri içine giren intihar girişimine müdahale konusunda bu tür eksiklikler olduğu gözlenmiştir. Herhangi bir sağlık kuruluşuna başvuran intihar girişimli hasta hakkında gerekli bilgilerin edinilmesi, uygun tedavi ve sevkin sağlanmasł acil hizmetlerin hızlı temposunda henüz rayına oturmuş gözükmemektedir.

Intihar girişimi konusunda beliril aralıklarla tekrarlamalı ve ayrıntılı çalışmaların ozzellikle önleme açısından geliştirilecek programlara katkısı olacağı düşünülmektedir. Bu nedenle de uygun kayıt sistemleri sağlamak ve bunların uygulama fırsatlarını yaratmak önemli bir konu olarak gözükmektedir. Bu amaçla hastane acil servisleri ve adii vak'a bilgilerinin kullanslabilir nitelikte elde edilmesini sağlama için intihar ve intihar girişimi bilgi toplama formu hazırlanması ve kurumlarla işbirliği yapıimasının olumlu sonuçlar getireceği düşünülmektedir.

\section{KAYNAKLAR}

Alderson, M.R. (1985) National tends in self-poisoning in women. The Lancel, April 27:974-975.

Aydin, H. ve ark., (1988) intihar davranısmm sosyodemografik özellikleri. XXIV. Psikiyatri ve Nörolojik Bilimler Kongresi Bilimsel Çalısmaları. I Saypa Ankara, 238-247

Aydin, H. ve ark., (1988) intihar davramışinın gruplar uzerine etkileri. XXIV. Ulusal Psikiyatri ve Norolojik Bilimier Kongresi Bilimsel Calısmaları . I.Saypa, Ankara, 530.536.

Bille-Brahe, U. (1990) Suicide and attempted suicide in a representative danish area in the late 1970's and the late 1980's. Ferrari, G., Bellini, M., Crepet P. (Eds). 3rd European Symposium Suicidal Behaviour and Risk Factors, Manduzzu Editore, Bologna.

DiE (1990) Intihar istatistikleri. DiE Matbaas!, Ankara.

Diekstra, R.F.W. ve ark. (1981) On the epidemiotogy of attempled suicide. Soubrier J.P., Wedrinne J. (Eds) Depression and Suicide, Paris. Pergamon Press,

Diekstra, R.F.W. (1989). Suicide and the attempted suicide: An International penspective. Acta Psychiatr. Scand 80(Suppl. 354): $7-24$.

Ekşi, A. (1988) Cocuk ve Ergenlerde Intihar. XXIV. Ulusal Psikiyatri ve Nörolojik Bilimler Kongresi. Bilimsel Çalsşmaları II.VDK. Ankara134-155.

Etzersdorfer ve ark. (1991). Where do the suicide attempts in Vienna get lost ? XVI IASP-Congress International Conference on Suicide Prevention and Crisis Intervention. 1-5 September 1991, Hamburg.

Gürgen, F. (1989) Diyarbakur kent merkezinde hava sıcakhı̆ı ile homicide, suicide, yaralanma ve trafik kazasi olgularm n iliskisi (1983-1987). Dicle U. Tip. Fak. Dergisi, Cit 16, Sayl 1.

Hawton, K. (1988) Attempted Suicide. London: Oxford University Press.

Kucur, R., Aktan, K (1987) Konya merkez licesinde 1986 Yilinda Suicide insidanst. XXIII. Ulusal Psikiyatri ve Nörolojik Bilimler Kongresi, Bilimsel Callsmalari, Onur ofset, istanbu 299-305. 
Kucur, A. (1988) Konya'da Intihar Insidanst ve önleyici tedbirler. XXIV Ulusal Psilkyyatri vo Nörolojik Bilimier Kongresi Bilimsel Calısmalan! II VDK, Ank, 249-256.

Lester, D., ICll, T. (1990) Amerikalı ve Türk ogfrencilerin intihar hakkindaki inanclarl. The J. of Social Psychology, 130(6):825-827.

Ozbek, A. ve ark. (1987) Açk Tedavi ortaminda Inthar girisimimi Vak'alarnin degerlendirilmesi. XXIII. Ulusal Psikiyatri ve Nörolojik Bilimler Kongresi, Bilimsel Calşmalar, Onur Otset, istanbul 321-327.

Ozşahin, A. ve ark. (1988) Inthar girişimi sonucu acil servise başvuranjar ustüne bir çalışma. XIV Ulusal Psikiyatri ve No rolollk Bllimier Kongresi, Bilimsel Calkşmalan I. Saypa, Ankara, 208-214.

Palabrykoğlu, R. (1990) Ergenlik döneminde intihar davranışı. A.U. Psikiyatrik Kriz Uygulama ve Araştrma Merkezi Oneğtim Çalışmalari, 1-30 Mart.

Parker, G. ve Walter, S. (1982) Seasonal variation in depressive disorder and suicidal deaths in New South Wales. British J. of Psych, 140:626-632.

Sayl, I. (1987). Statistical data on suicide in Turkey. Yufit R.I. (Ed), Proceedings 20th Annual Conference on AAS and IASP, Sen Fransisco.U.S.A.

Sayll, I. ve ark. (1988) Psikotik hastalarla grup todavisi uygulamalarnda intihar olgusunun islenisi. XXIV. Ulusal Psikiyatri ve Nórolojik Bilimler Kongresi, Bilimsel Çalışmaları, I Saypa, Ankara, 553-558.

Sonuvar, B. , Oktem, F. (1986) Çocuk ve genclerde inthar girisim. Tophum vo Hokim, Mart, 16-22.

Taneli, S. (1981) inthar ve inthar girişimferi. Bursa Tip Fakütesi Dergisi, Sayi:3, 1-25.

Tuncer, C., Oral, T. (1988) Hekinter arasi inthartar. Motroloji, nörossinurji, Psikiyatri Dergisi, 3(2) Ocak 